\title{
TUTURAN TOLEA DALAM RITUAL PESTA ADAT MOSEHE WONUA SUKU TOLAKI MEKONGGA DI KABUPATEN KOLAKA: TINJAUAN SEMIOTIKA
}

\author{
Sultan, Tadjuddin Maknun, Ikhwan M. Said \\ Jurusan Linguistik, Fakultas Ilmu Budaya, Universitas Hasanuddin \\ usn.sultan@gmail.com
}

\begin{abstract}
This research is a qualitative descriptive study, Research location in Kolaka District, The data source is the meaning of the Kalo Sara symbol obtained from the Mekongga Mosehe Wonua custom ritual in Kolaka District, either words, phrases, or sentences. Duration of study, ie June 2015 to end of April 2016. The results of this study indicate that the first meaning of Tolea speech in every stage of the speech Tolaki Society in Mekongga Southeast Sulawesi make the speech disclosed Tolea at the beginning or opening speech is a symbol. The meaning In the opening speech is a symbol of respect. In the core speech is a symbol of obedience in ritual. In the closing speech of Tolea is a symbol of appreciation. The two functions of Tolea's utterance in the Mosehe Wonua ritual in Kolaka District, which contains a prominent religious significance in the Mosehe Wanua ritual ceremony of the Tolaki community in Mekongga Southeast Sulawesi is a form of public confidence in the influence of ancestors and customs in every procession

Keywords: Tolea Tutorial, Mosehe Wonua Tradition, Semiotics.
\end{abstract}

\section{A. PENDAHULUAN}

Kebudayaan lokal merupakan pandangan yang menyeluruh bagi suatu etnik tertentu menyangkut pandangan hidup, sikap, dan sistem nilai dalam kehidupannya. Dengan kata lain, kebudayaan suatu etnik merupakan instrumen atau alat dalam kehidupan masyarakatnya dengan nilai-nilai yang terkandung dalam kebudayaannya menjadi patokan sekaligus menjadi tujuan hidupnya. Salah satu wujud kebudayaan yang dimiliki oleh masyarakat Kendari, yakni tuturan yang diungkapkan oleh pemangku adat masyarakat setempat. Tuturan yang diungkapkan, tidak serta merta diketahui makna yang terkandung dalam tuturannya tersebut. Pada sisi yang sama, masyarakat sebagai pelaku kebudayaan kurang menumbuhkan rasa tanggung jawab diri sebagai pewaris tradisi Mattulada (1985:12).
Suatu tanda menandakan sesuatu selain dirinya, dan makna (meaning) ialah hubungan antara suatu objek atau idea dan suatu tanda. Tanda-tanda (signs) adalah basis dari seluruh komunikasi. Tanda sebagai suatu keterhubungan antara wahana ekspresi (expression plan) dan wahana isi (content plan). Tanda, dalam pandangan Pierce adalah sesuatu yang hidup dan dihidupi (cultivated). Tanda hadir dalam proses interpretasi (semiosis) yang mengalir. Kajian semiotika dapat dapat dibedakan menjadi dua jenis, yakni semiotika komunikasi dan semiotika signifikasi. Semiotika komunikasi menekankan pada teori tentang produksi tanda, sedangkan semiotika signifikasi memberikan tekanan pada teori tanda dan pemahamannya dalam suatu konteks tertentu Sobur (2006:15)

Bagi Peirce (dalam Anwar, 2008:3) semiotika adalah proses simbolisasi atau representasi (semiosis). Proses, yaitu 
dinamika yang terpadu di dalamnya tiga unsur dinamis, yakni tidak lengkap, tidak final, dan tidak pasti. Dalam teorinya tentang tanda. Peirce mendefenisikan sebagai representasi terhadap sesuatu bahwa ia mampu menyampaikan sebagian sisi atau dayanya kepada orang lain. Peirce merujuk kepada doktrin formal tentang tanda-tanda, jadi yang menjadi dasar dari semiotika adalah konsep tentang tanda.

Langer (1976:60), mengatakan bahwa kebutuhan akan simbolisasi adalah kebutuhan mendasar yang dimiliki oleh manusia. Menurutnya, fungsi pembentukan simbol ini adalah satu di antara kegiatankegiatan dasar manusia, seperti makan, melihat dan bergerak. Ini adalah proses fundamental dari pikiran dan berlangsung setiap waktu.

Menurut Mazi (2004), setiap tanda selalu memperoleh pemaknaan awal yang dikenal dengan istilah denotasi dan oleh Barthes disebut sistem primer, Kemudian pengembangannya disebut sistem sekunder. Sistem sekunder ke arah ekspresi disebut metabahasa atau bermakna ganda.Para ahli semiotika jenis ini tanpa merasa keliru dalam bidang metodologi, mencampurkan analisis mereka dengan pengertian-pengertian dari dua aliran hermeutika yang sukses zaman itu, yakni Psikoanalisis dan Marxisme.

Menurut Kridalaksana (1993:132), bahwa makna merupakan maksud pembicaraan, pengaruh suatu bahasa dalam pemahaman resepsi atau prilaku manusia; hubungan dalam arti kepadanan antara bahasa dan luar bahasa atau antara ujaran dan semua lambang yang ditujukannya, dan cara menggunakan lambang-lambang bahasa.

Djajasudarma

(1993:136),

mengartikan makna sebagai pertautan antara unsur dalam suatu bahasa. Makna merupakan esensi dari studi bahasa. Jika demikian, pemakaian bahasa, termasuk tuturan ritual masyarakat Tangru dipandang sebagai identitas yang memiliki makna. Di samping makna, pemakaian bahasa ritual menyiratkan nilai budaya di balik makna yang dimaksud. Nilai budaya bersifat abstrak yang menjadi pedoman bertutur dan berbudaya berdasarkan prinsip dalam berprilaku. Nilai itu bukan berupa benda atau unsur dari benda, melainkan sifat dan kualitas yang dimiliki objek tertentu yang dikatakan baik.

Menurut Hadi (1999:29-30) ritual merupakan suatu bentuk perayaan yang berhubungan dengan beberapa kepercayaan atau agama ditandai dengan sifat khusus, yang menimbulkan rasa normal atau seperti biasa yang dirasakan oleh semua manusia dan yang luhur dalam arti merupakan suatu pengalaman yang suci. Berkaitan dengan hal tersebut ritual kematian adalah upacara memanjatkan doa keselamatan kepada mendiang. Ritual kematian masyarakat Tangru merupakan suatu upacara berupa serangkaian tindakan yang dilakukan sekelompok orang menurut adat kebiasaaan setempat, yang menimbulkan rasa hormat yang luhur sebagai suatu pengalaman suci. Endaswara (2003:175), mengklasifikasi ritual menjadi dua. Pertama, ritual krisis hidup, artinya ritual yang berhubungan dengan krisis hidup manusia. Manusia pada dasarnya akan mengalami krisis hidup, ketika masuk dalam peralihan. Pada masa ini, dia akan masuk dalam lingkup krisis karena terjadi perubahan tahapan hidup termaksud dalam lingkup ini antara lain kelahiran, pubertas dan kematian. Kedua, ritual gangguan, yakni ritual sebagai negosiasi dengan roh agar tidak menggangu hidup manusia. Ritual semacam ini dalam masyarakat Mandar sering diwujudkan dalam tradisi selamatan.

Ritual akan mampu melepaskan tekanan-tekanan social bahwa sistem upacara merupakan wujud kelakuan dan religi dan seluruh sistem upacara itu terdiri atas aneka macam upacara yang bersifat harian, musiman dan kadang kala. Dalam sistem upacara keagamaan terkandung 
empat aspek, yaitu (1) tempat upacara keagamaan, (2) tempat pelaksanaan upacara, (3) waktu pelaksanaan upacara, dan (4) benda-benda dan peralatan upacara serta orang yang melakukan dan memimpin jalannya upacara Koentjaraningrat (2004:147).

sebagai peneliti tertantang di atas, mengungkapkan tuturan Tolea sebagai sebuah bentuk tradisi yang berupa simbol dan menyiratkan makna tersendiri dalam kehidupan suku Mekongga. Tuturan Tolea dan makna serta fungsi Kalo Sara seharusnya diketahui oleh masyarakat sebagai suku Tolaki, namun masyarakat setempat tidak mengetahui makna tuturan dan benda Kalo Sara. Simbol-simbol dalam Kalo Sara memiliki makna tersendiri. Oleh karena itu tujuan dari penelitian ini, yaitu mendeskripsikan makna tuturan Tolea dalam ritual Mosehe Wonua di Kabupaten Kolaka, mendeskripsikan fungsi tuturan Tolea dalam ritual Mosehe Wonua di Kabupaten Kolaka.

\section{B. BAHAN DAN METODE}

\section{Jenis Penelitian}

Penelitian ini merupakan Penelitian kualitatif. Segala permasalahan diidentifikasi, dibahas, dan dikaji secara mendalam. Selanjutnya, diperoleh gambaran atau penjelasan tentang hal-hal yang berhubungan dengan fenomena permasalahan. Dengan menggunakan metode deskriptif, berarti penelitian dilakukan semata-mata hanya berdasarkan fakta yang ada atau fenomena secara empiris hidup pada penuturnya. Dengan metode deskriptif akan didapatkan deskripsi data secara alamiah. Langkah selanjutnya, yaitu melakukan pengumpulan data dengan cara pencatatan, penelaan data, pengklasifikasian data, penganalisaan data, dan penyimpulan data.

\section{Lokasi dan Waktu}

Lokasi penelitian, yaitu Kabupaten Kolaka. Wilayah Kabupaten Kolaka merupakan daerah yang representatif, sangat mendukung untuk dijadikan tempat penelitian.

\section{Sumber Data}

Sumber data dalam penelitian ini terdiri atas dua sumber. Pertama, data primer, yaitu data berupa makna simbol Kalo Sara yang diperoleh dari ritual Mosehe Wonua adat Mekongga di Kabupaten Kolaka, baik berupa kata, frasa, maupun kalimat. Data sekunder, yaitu data tambahan yang diperoleh dari buku-buku yang ada kaitan dan mendukung penelitian ini.

\section{Teknik Pengumpulan Data}

Teknik pengumpulan data yang digunakan adalah Dalam mengungkapkan dan membahas mengenai ritual adat Kalo Sara ini, peneliti menggunakan beberapa cara dalam mengumpulkan data, yaitu teknik rekam, teknik catat, dan teknik observasi langsung. Tekniki rekam yaitu merekam sejumlah bentuk dan simbol Kalo Sara.Teknik catat, dilakukan dengan mencatat informasi tambahan dari penyelenggara adat.Wawancara, baik secara formal maupun informal. Wawancara ini bertujuan memperkuat apa yang telah didapat dari observasi langsung.

\section{Analisis Data}

$\begin{array}{ccr} & \text { Analisis data merupakan sebuah } \\ \text { proses } & \text { mengorganisasikan dan }\end{array}$ mengurutkan data ke dalam pola, kategori, dan satuan uraian dasar sehingga dapat ditemukan tema dan dapat dirumuskan hipotesis kerja seperti yang disarankan oleh data. Setelah data dari lapangan terkumpul dengan menggunakan metode pengumpulan data di atas, peneliti akan mengolah dan menganalisis data tersebut dengan menggunakan analisis secara deskriptif-kualitatif. Analisis deskriptifkualitatif merupakan sebuah teknik yang menyajikan dan menginterpretasikan makna serta maksud dari data-data yang telah terkumpul dengan memberikan 
perhatian dan merekam sebanyak mungkin aspek situasi yang diteliti pada saat itu sehingga diperoleh gambaran secara umum dan menyeluruh tentang keadaan yang sebenarnya.

\section{HASIL}

Hasil penelitian Hasil analisis data ditemukan bentuk tuturan pada setiap bagian teks tuturan Tolea dalam tradisi mosehe wanua masyarakat Tolaki di Mekongga Sulawesi Tenggara yakni tuturan pembuka, tuturan inti dan tuturan penutup. Makna tuturan Tolea disetiap tahapan tuturan yaitu Masyarakat Tolaki di Mekongga Sulawesi Tenggara menjadikan tuturan yang diungkapkan Tolea pada awal atau tuturan pembukanya merupakan sebuah simbol. Menurut Peirce dalam trikotominya, mengungkapkan bahwa simbol merupakan konvensi atau kesepakatan bersama yang berlaku dalam komunitas atau masyarakat tertentu dengan meyakini kebenaran atas apa yang telah disepakati. Pada tuturan pembuka yang diungkapkan Tolea dalam ritual Mosehe Wanua masyarakat Tolaki di Mekongga Sulawesi Tenggara adalah tanda yang merupakan simbol penghormatan dalam ritual tersebut.

\section{Makna Tuturan Tolea}

\section{Tuturan Pembuka}

Tuturan pembuka merupakan teks yang dituturkan oleh Tolea atau juru bicara yang dalam tuturannya mengandung tentang permohonan izin kepada pihakpihak yang diagungkan dalam membuka atau memulai kegiatan ritual MW pada masyarakat Tolaki di Mekongga Sulawesi Tenggara. Pada bagian ini, Tolea yang menjadi juru bicara adat masyarakat setempat dalam ritual Mosehe Wanua mengungkapkan tuturan yang dinyatakan dalam prosesi tradisi masyarakat Tolaki di Mekongga Sulawesi Tenggara sebagai berikut:

Dialog 1
Tabea inggomiu pak Bupati ulu sala, mandarono olipu wonua i Kolaka, la pinoko owosenggu pinoko lalo inggu ronga wakili, tabea inggomiu wakele bupati, la ladumisioro tinamuako teeni pamarenda owose

Pada tuturan diatas dimaksudkan sebagai penghormatan dan penghargaan bagi Pak Bupati dan wakil Bupati sebagai ulu sala 'kepala pemimpin' di wilayah Mekongga Kabupaten Kolaka. Pada data (T1) menggunakan kata tabea 'yang terhormat' merupakan kata pembuka atau kata yang selalu dipakai untuk mengawali sebuah percakapan atau tuturan.

Tuturan pembuka atau pondorambuu pada ritual Mosehe Wonua ini memperlihatkan tuturan yang terstruktur atau beruntutan dalam setiap kalimatnya. Setiap kalimat yang disajikan dalam tuturan pembuka oleh tolea (pembicara) tersebut mengandung bahasa sopan yang menggunakan intonasi yang halus yaitu penekanan kata tabea 'yang terhormat' salah satunya terlihat pada contoh kalimat: Tabea inggomiu Pak Bupati ulu sala 'yang terhormat Bapak Bupati sebagai kepala pemimpin'.

Konteks pada dialog pertama pada saat menuturkan tuturan pembuka (Tolea berinteraksi dengan Raja Mekongga, Bapak Bupati, dan Wakil Bupati beserta sanak saudara, mereka saling berhadapan dan benda kalo sara digenggam oleh tolea sebagai wujud mediasi penghubung dialog antara raja atau Bapak Bupati dengan Tolea). Kemudian, Raja Mekongga bersama yang lainnya menyambut sambutan tolea sebagai tanda penerimaan permintaan izin dalam melanjutkan ritual tersebut.

\section{Tuturan Inti'}

Pada bagian tuturan inti merupakan bagian inti dari ritual mosehe wanua yang merupakan lanjutan dari tuturan pembuka. Pada tuturan inti juru bicara adat (tolea) mengawali pembicaraannya bermaksud 
untuk menyampaikan sepatah kata kepada Raja Mekongga, Bapak Bupati, dan wakil Bupati serta sanak saudara yang diagungkan untuk melanjutkan ritual dari mosehe wonua sebagai wujud penghormatan dan permohonan izin atau restu baik untuk melanjutkan ritual yang dianggap inti pada dialog ini untuk diperdengarkan oleh seluruh masyarakat Tolaki. Setiap kata yang dituturkan oleh tolea dalam kegiatan adat atau penyucian suatu wilayah atau dikenal sebagai Mosehe Wonua ini tidak pernah mengalami perubahan tuturan seperti yang tergambar pada tuturan dibawah ini:

\section{Dialog 2}

Iye inggomiu pak bupati ulu sala mandarano olipu petumbuno wonua tusatongano olipu,lamenggokooro meita mendo tooro nde pekulaso mendongano olipu wonuai i kolaka, lmendongano toono dadio $i$ wonuai kolaka, laa tudu inggomiu sara owose,sara pamarenda, sara mbe paramisi, membo kulaloi lako keinggomiu keno lando osala pewali niru ku toono sdadio,inggomiu odisi pamarenda,inggo mohu nggo mondiso,osala, tewali, niruku toono dadio.ki inggo to meruhu aki mo rongo rongo meteo olu pohu pondisomiu,

Makna yang ingin disampaikan pada tuturan inti diatas, berisi tentang aturan atau petunjuk adat yang bertujuan agar masyarakat mematuhi atau menghormati adat mosehe wonua.

Ritual Mosehe Wonua ini bermula dari aturan Raja yang berkuasa Kerajaan Mekongga terdahulu dan masih dilaksanakan oleh masyarakat sekarang. Kegiatan adat ini diselenggarakan 5 tahun sekali sebagai kebiasan oleh masyakarat Mekongga dengan maksud meminta atau memohon perlindungan atau keselamatan dari bencana alam.

Penggalan tuturan Tolea yang
menjadi bagian tuturan inti yang diungkapkan dalam ritual Mosehe Wanua masyarakat Tolaki di Mekongga Sulawesi Tenggara, menjadi sebuah pegangan atau pedoman yang menjadi landasan atau dasar dalam menjalankan tradisi atau ritual Mosehe Wanua masyarakat Tolaki di Mekongga Sulawesi Tenggara. Semua tuturan yang diungkapkan Tolea pada penggalan bagian inti ini menjadi suatu yang dianggap sakral dari segi histori dan idiologi masyarakat setempat.

Pada tuturan inti yang diungkapkan Tolea dalam ritual Mosehe Wanua masyarakat Tolaki di Mekongga Sulawesi Tenggara ini merupakan tanda yang menjadi simbol yang dalam tuturan tersebut menyiratkan makna yang sangat diyakini oleh masyarakat setempat. Tuturan yang diungkapkan Tolea dalam ritual ini telah diketahui secara saksama oleh masyarakat, namun masyarakat setempat tidak mengetahui makna yang terkandung dari tanda yang terkandung dalam tuturan tersebut. Keyakinan masyarakat sudah membentuk sebuah konvensi atau kesepakatan yang telah diyakini bersama sebagai sebuah kebenaran yang mutlak.

\section{Tuturan penutup}

Bentuk tuturan yang diungkapkan oleh Tolea dalam ritual Mosehe Wanua masyarakat Tolaki di Mekongga Sulawesi Tenggara merupakan penggalan tuturan yang dikategorikan sebagai tuturan penutup. Tuturan penutup merupakan tuturan akhir dari tuturan yang diungkapkan Tolea pada ritual Mosehe Wanua masyarakat Tolaki di Mekongga Sulawesi Tenggara.

Pada tuturan penutup, Tolea menuturkan permohonan izin kepada raja, dewan adat, bupati, dan wakil bupati dengan bahasa yang halus yang dilalamnya menyiratkan makna yang dalam tuturannya dipahami oleh semua pihak yang terlibat dalam prosesi ritual Mosehe Wanua masyarakat Tolaki di Mekongga Sulawesi Tenggara. Ungkapan permohonan izin dalam tuturan penutup dapat kita lihat pada teks dibawah ini: 
Dialog 3

Tabea inggomiu odisi pamarenda, owose pak bupati, wakili bupati tabea inggomiu bokeo anakia owose wonua $i$ mekongga, monguni tarimakasi lako hano miu.Iyye inggomiu mbera anakia owose se nusantara,iyye inggomiu mbera mokole ronga susunano bokeo anakia i mekongga. Iyye inggomiu inalolo ina luwako la la panggano ronga perehu rehu ano, $i$ podedai ariya ku to masima ke ito mongoni paramisi, inedisi pamarenda la ito pohu uno tini sono tewali niru kundo to onggoto moko lako pasipole ohawo la otuando tola mende konggo mende perimbu, ni inono pasipole topoko lakoito.

Iyye inggomiu ina lolo ina luwuako la la mendo otoro, la la tekonggo mbera toka ikeni kula mekodunggo iko miu, ilako keeto pasipole.

Tuturan Tolea diakhir yang merupakan tuturan penutup, bagian tuturan Tolea yang menjadi bagian tuturan akhir atau penutup yang diungkapkan dalam ritual Mosehe Wanua masyarakat Tolaki di Mekongga Sulawesi Tenggara merupakan bentuk pemujaan terhadap leluhur yang menciptakan dan menghadirkan tradisi yang masih hidup hingga kini, selain itu tuturan Tolea tersebut merupakan bentuk penghargaan yang setinggi-tingginya terhadap raja dan petinggi pemerintahan yang hadir dalam ritual Mosehe Wanua masyarakat Tolaki di Mekongga Sulawesi Tenggara. Dalam tuturan akhirnya, tolea mengungkapkan rasa terima kasih dan penghargaan yang setinggi-tingginya kepada semua pijhak yang hadir dalam tradisi Mosehe Wanua ini pada masyarakat Tolaki di Mekongga Sulawesi Tenggara.

Tuturan penutup yang diungkapkan Tolea dalam ritual Mosehe Wanua masyarakat Tolaki di Mekongga Sulawesi Tenggara ini merupakan tanda yang memiliki makna dan menjadi simbol bagi masyarakat setempat. Tuturan yang diungkapkan Tolea dalam ritual ini telah diketahui secara saksama oleh masyarakat, namun masyarakat setempat tidak mengetahui makna yang terkandung dari tanda yang terkandung dalam tuturan penutup tersebut. Keyakinan masyarakat sudah membentuk sebuah konvensi atau kesepakatan yang telah diyakini bersama sebagai sebuah kebenaran mutlak yang dianut oleh masyarakat setempat.

Masyarakat Tolaki di Mekongga Sulawesi Tenggara menjadikan tuturan yang diungkapkan Tolea pada bagian penutup atau akhir yang juga penting untuk disampaikan dan didengar oleh semua yang hadir di pesta adat tersebut. Tuturan penutup Tolea itu merupakan sebuah simbol yang memiliki makna. Menurut Peirce, mengungkapkan bahwa simbol merupakan konvensi atau kesepakatan bersama yang berlaku dalam komunitas atau masyarakat tertentu dengan meyakini kebenaran atas apa yang telah disepakati. Pada tuturan penutup Tolea dalam ritual Mosehe Wanua masyarakat Tolaki di Mekongga Sulawesi Tenggara merupakan simbol penghargaan.

\section{KESIMPULAN}

Berdasarkan hasil analisis data di
bagian pembahasan, maka dapat dikemukakan simpulan, yaitu ditemukan bentuk tuturan pada setiap bagian teks tuturan Tolea dalam tradisi mosehe wanua masyarakat Tolaki di Mekongga Sulawesi Tenggara yakni tuturan pembuka, tuturan inti dan tuturan penutup. Makna tuturan Tolea disetiap tahapan tuturan yaitu Masyarakat Tolaki di Mekongga Sulawesi Tenggara menjadikan tuturan yang diungkapkan Tolea pada awal atau tuturan pembukanya merupakan sebuah simbol. Menurut Peirce dalam trikotominya, mengungkapkan bahwa simbol merupakan konvensi atau kesepakatan bersama yang berlaku dalam komunitas atau masyarakat tertentu dengan meyakini kebenaran atas 


\section{7 | JURNAL ILMU BUDAYA}

apa yang telah disepakati. Pada tuturan pembuka yang diungkapkan Tolea dalam ritual Mosehe Wanua masyarakat Tolaki di Mekongga Sulawesi Tenggara adalah tanda yang merupakan simbol penghormatan dalam ritual tersebut. Disarankan agar penelitian ini menjadi dasar dan panduan untuk melanjutkan penelitian dengan sudut pandang dan pisau analisis yang berbeda, sehingga memberikan khazanah baru dan sumbangsi pemikiran dari hasil penelitian yang dilakukan.

\section{DAFTAR PUSTAKA}

Anwar, Ahyar. (2008). Semiotika Sastra. Makassar: UNM.

Djajasudarma, Fatimah. (1993). Semantik I Pengantar ke arah Ilmu Makna. Bandung: Refika Aditama

Endraswara, Suwardi. (2003). Metodologi Penelitian Sastra. Yogyakarta: Pusaka Widyatama.

Mattulada. (198)5. Latoa: Satu Lukisan Analitis Terhadap AntropologiPolitik. Makassar: LEPHAS.
Mazi, Ali. (2004). Peranan Nilai-nilai Budaya Lokal dalam Pelaksanaan Pembinaan Teritorial di Sulawesi Tenggara. Kendari: Tanpa Penerbit.

Hadi, Sumandiyo. (1999). Seni dalam Ritual Agama. Jakarta: Yayasan untuk Indonesia.

Hasyim, Muhammad. 2017. The Metaphor of Consumerism. "Journal of Language Teaching and Research", Vol. 8, No. 3, pp. 523-530.

Kridalaksana, Harimurti. (1993). Kamus Linguistik. Jakarta: PT Gramedia Pustaka Utama.

Koentjaraningrat. (2004). Kebudayaan Mentalis dan Pembangunan. Jakarta : PT Gramedia Pustaka Utama.

Langer, Susanne. (1976). Problem of Arts, edition-6. New York: Charles Sribners Sons.

Sobur, Alex. (2004). Analisis Teks Media. Bandung: PT Remaja Rosdakarya. 